\title{
Information Externalities and Intermediaries in Frictional Search Markets*
}

\author{
Xianwen Shi and Aloysius Siow ${ }^{\dagger}$
}

September 3, 2013

\begin{abstract}
In frictional matching markets with heterogeneous buyers and sellers, sellers incur discrete showing costs to show goods to buyers who incur discrete inspection costs to assess the suitability of the goods on offer. This paper studies how brokers can help reduce these costs by managing the level and mix of goods in their inventory. We find that intermediaries emerge and improve social welfare when there is sufficient heterogeneity in the types of goods and preferences. Our analysis highlights how learning and inventory management enable search intermediaries to internalize information externalities generated in unintermediated private search.
\end{abstract}

${ }^{*}$ We thank Ettore Damiano, Jean Guillaume Forand, Robert McMillan, Carolyn Pitchik, Shouyong Shi, Matt Turner, Asher Wolinsky, Andriy Zapechelnyuk, and seminar participants at Peking University, Queen's University, University of Toronto, and Econometric Society World Congress at Shanghai for helpful comments and suggestions. We are grateful to three anonymous referees for many constructive comments. We also thank Lucas Siow for research assistance. The first author is grateful to the Alexander von Humboldt Foundation for financial support and to the Chair of Economic Theory II at University of Bonn for its hospitality where part of this work was completed. Both authors also thank SSHRC for financial support. This paper was previously circulated under the title of "Search Intermediaries".

${ }^{\dagger}$ Department of Economics, University of Toronto, 150 St. George Street, Toronto, ON M5S3G7, Canada. Email: xianwen.shi@utoronto.ca, siow@chass.utoronto.ca. 


\section{Introduction}

In many frictional matching markets, heterogenous buyers and heterogenous sellers (characterized by different types of goods) search to match and trade with each other. Upon meeting a seller, a buyer has to inspect the good on offer to see if it matches his preference. If there is no trade, both the buyer and seller will separate and continue to search for other trading partners. While a buyer's preference and the characteristics of a good are persistent over time, buyers and sellers exit the market after trade and they seldom return. Intermediaries are active in some of these markets and not others. What is their role?

The leading example of such a market with intermediaries is the residential housing resale market where the majority of transactions are brokered by real estate agents. Houses are different and a description in an online listing service, such as the Multiple Listing Service, does not describe a house completely. Thus a buyer must incur a costly personal inspection of the house in order to investigate all its attributes. Similarly, a seller also has to incur a discrete showing cost to show the house to interested buyers. ${ }^{1}$ Therefore, both buyers and sellers in the housing market would like to reduce inspection or showing costs by avoiding unnecessary but costly home inspections.

Another example is the market for corporate executives where headhunters, as intermediaries, play an important role in matching workers with vacancies. Based on interviews with headhunters, Finlay and Coverdill (2002) conclude that the success of a placement in this market depends on both tangible information about candidates and employer preferences revealed through job advertisements and resumes, and intangible ones revealed through subsequent costly interviews. In other labor markets such as retail sales, workers and employers often match directly without using employment agencies. There is one important difference between labor markets which use intermediaries in hiring versus those which do not: the degree of heterogeneity across workers and across employers.

The objective of this paper is to investigate the role of intermediaries in reducing inspection and showing costs in the standard framework of two-sided sequential search. We study how intermediaries use both the level and the mix of inventory to reduce these costs. The degree of heterogeneity in goods/preferences plays a crucial role in our theory. Although the model is not specific to a particular market, we will use the housing market as an ongoing example to provide context for the model.

\footnotetext{
${ }^{1}$ The assumption of imperfect advertising of homes for sale is a common one in search models of housing market (e.g., Wheaton 1990).
} 
To see the advantage an intermediary may have, first consider a market without brokers. Both houses and buyers' preferences are fixed and horizontally differentiated. Suppose a buyer values a house only if the characteristics of the house (seller type) fit his preference (buyer type). Both house characteristics and buyers' preferences are difficult to articulate or describe completely a priori. Each period buyers and sellers in the market search for trading opportunities. When a type $A$ buyer randomly meets a type $b$ seller, the buyer incurs an inspection cost and the seller incurs a showing cost, the buyer finds out that the house is type $b$ and decides not to buy it. The information that the house is type $b$ has no value to this buyer for his own future search, and similarly, the information that the buyer is type $A$ has no value to the future search of this seller. The information, however, is valuable for other buyers and sellers to avoid incurring unnecessary search costs. Since communication with other potential trading partners is costly, neither the type $b$ seller nor the type $A$ buyer has incentive to pass the information on to others. As a result, there are information externalities: some socially useful information generated in private search is lost and not efficiently utilized.

Such information externalities are crucial for our theory. Three assumptions are key for information externalities to arise in unintermediated private search. First, goods and buyers' preferences are heterogeneous, which creates the possibility of mismatch. Second, preferences or product characteristics, especially those intangible ones, cannot be communicated easily among trading partners. A seller has to incur a showing cost and a buyer has to incur an inspection cost to find out whether the buyer's preference matches the type of the good. Moreover, once a seller incurs a cost and learns the preference of a buyer, she can remember the buyer's preference, but it is again costly for her to communicate the preference to another seller. Communication barriers could arise because language is vague or there is language barrier (Lipman 2009, Blume and Board 2012). Third, buyers' preferences are persistent. Hence, information about a particular buyer's preference, though not useful for the current seller in case of mismatch, is valuable for the buyer's future trading partners to avoid unnecessary screening costs.

Now consider such a market with seller brokers. Suppose these brokers do not have any inspection or showing costs advantage over buyers and sellers. A broker has to look for sellers to represent. Upon meeting a potential client, the broker has to pay an inspection cost and the seller has to incur a showing cost for the broker to inspect the good to determine its type. After an agreement to represent the seller, the broker also has to pay a showing cost to show the good to any potential buyer. ${ }^{2}$

\footnotetext{
${ }^{2}$ After signing up a seller broker, the broker will carry out the subsequent showings of the house
} 
Thus employing a broker to complete a transaction incurs additional screening costs which are absent without such a broker.

A broker's advantage in the market comes from the possibility that a broker can represent more than one type of sellers. In this case, it is advantageous for a buyer to contact a broker, because after the broker learns of the buyer's type through a first showing, the broker can economize on further showing costs and inspection costs by not showing other goods that the buyer will not be interested in. For example, suppose a type $A$ buyer randomly meets a broker who represents two different houses, say type $b$ and $c$. After showing house $b$ to the buyer, the broker learns that the buyer is type A. ${ }^{3}$ Then the broker can tell the buyer that there is no need for him to see the second house because it does not fit, saving screening costs for both parties. This advantage can be materialized only when the broker has additional goods in his inventory which are of potential interest to the buyer. Each seller hires a costly broker because the broker has other types of goods in his inventory to attract potential buyers. ${ }^{4}$ Thus brokers have to actively manage both the level and mix of goods that they represent.

We first study the case of seller brokers. A seller broker first picks up seller representations from the sellers' market and then sells houses to buyers on the sellers' behalf in the buyers' market. We restrict our brokers to represent at most two clients at a time. This is the minimal size of inventory needed for brokers to exist. In order to tease out the intermediaries' role in reducing discrete search costs from their other roles, our analysis primarily focuses on the limit equilibrium as the discount rate goes to zero. In the limit equilibrium, brokers exist and improve welfare if there is sufficient heterogeneity in the types of buyers and goods. Furthermore, brokers reduce the expected total inspection and showing costs by all parties needed to complete a transaction. Because the number of houses seen by a buyer is a good proxy for the buyer search duration while the number of showings by a seller is a good proxy of the time on the market, our model predicts that the real-estate brokers reduce the expected time for a seller to sell a house and a buyer to buy a house, which is a robust finding of empirical studies on the role of real estate brokers (see for example, Baryla and Zumpano 1995, Hendel, Nevo, and Ortalo-Magne 2009, Bernheim and

and thus incur all the subsequent showing costs. If the broker finds a buyer that likes the house, then the seller needs to incur one last showing cost (bargaining cost etc.) in order to finalize the transaction.

${ }^{3}$ It is not critical that the broker learns the buyer preferences perfectly. Appendix B extends the analysis to the setting where the communication between buyers and brokers is noisy.

${ }^{4}$ The argument is reminiscent of Wolinsky's (1983) argument for why competing retailers locate in shopping malls in spite of more intense price competition. By inspecting different goods in the same location, shopping malls help consumers save on travel costs. 
Meer 2008, among others).

We then extend the analysis to the case of buyer brokers who first seek buyer representations before going to the sellers' market to buy houses on the buyers' behalf. Again with sufficient heterogeneity, buyer brokers emerge and improve welfare in the limit equilibrium. However, for fixed model parameters, seller brokers and buyer brokers cannot be both welfare improving in equilibrium. In particular, welfare improving buyer brokers can exist only if the inspection cost is less than the showing cost, while welfare improving seller brokers can exist only if the reverse is true. The natural separation of the parameter space arises because in the case of buyer brokers the cost of intermediation (equilibrium commission fee) is primarily due to inspection costs in contrast to the case of seller brokers where showing costs make up the majority of the intermediation cost.

The remaining of the paper is organized as follows. The next section reviews related literature. There we discuss the connections and differences between this paper and related studies on search intermediaries. We then start with a two-sided search model without brokers in Section 3, which will serve as a benchmark for our analysis of brokers. The seller brokers are introduced into the model in Section 4. We show that seller brokers improve social welfare by reducing expected total numbers of showings and inspections necessary to complete a transaction. Section 5 briefly investigates the case of search with buyer brokers. Section 6 discusses a few extensions of the model and concludes. Several appendices collect technical results, one robustness check and some algebras that are omitted from the text.

\section{Related Literature}

Our paper belongs to the literature on search intermediaries starting with Rubinstein and Wolinsky (1987). This literature focuses primarily on the role of intermediaries in reducing delay costs, and typically assumes that intermediaries enjoy superior search technology than individual buyers or sellers. For example, in Rubinstein and Wolinsky, intermediaries or middlemen emerge and improve welfare because they can meet customers faster than buyers can meet sellers directly. In contrast, intermediaries in our model share the same search technology as buyers and sellers.

The two mostly closely related papers are Johri and Leach (2002) and Shevchenko (2004). In settings similar to ours with heterogeneous goods and tastes, Johri and Leach (2002) and Shevchenko (2004) assume middlemen have no inherent advantage in search technology and explore how middlemen, who can hold more than one unit of inventory, can generate welfare gains over unintermediated search. In Johri and 
Leach (2002), there are many infinitely lived consumers and suppliers. Each supplier can hold up to two units of heterogenous goods, and can produce one only if he does not currently hold any heterogenous goods. A supplier with one unit of good, defined as a producer, can become a middleman, defined as a supplier with two units of inventory, by picking up a second good from another supplier through random search, and a middleman can convert back to be a producer by selling one unit to a consumer, again through random search. Similar to our model, a buyer is better off meeting a middleman than meeting a producer, because a middleman with two heterogenous goods can generate a high matching value with higher probability for the buyer.

In Shevchenko (2004), each agent produces one type of goods, but desires to consume another so they search. If an agent randomly meets another agent, they trade only if there is a double coincidence. But if an agent randomly meets a middleman, double coincidence is not required, because middlemen are assumed to be endowed with a technology that can transform any good into a good they desire to consume. As a result, a trade occurs between an agent and a middleman as long as the middleman carries the good that the agent desires. Middlemen can increase trading probability by increase their inventory variety, but this comes at a cost which is increasing and convex. He derives both the optimal level of inventory and the equilibrium price distribution of goods. In Shevchenko (2004) and our model, the buyers' preferences are binary: a good is either acceptable or not, while Johri and Leach (2002) allows for more general preferences: a good is always acceptable to a buyer at certain price.

Both Johri and Leach (2002) and Shevchenko (2004) assume that the realization of matching value is independent across both units and buyer. Moreover, upon each meeting of a buyer and a middleman, the matching value is a fresh random draw and it is immediately revealed freely whether and how the buyer's preference matches any goods in the middleman's entire inventory. In contrast, in our model, both goods type and buyer type are persistent, and it is costly for both trading parties to find out whether the buyer likes any goods in the inventory. ${ }^{5}$ Therefore, the information externalities identified in this paper are absent in both Johri and Leach (2002) and Shevchenko (2004), and learning does not play a role since information is always revealed freely upon meeting. In our model, inventory per se does not automatically result in a cost advantage for intermediaries. It is the combination of inventory and learning that allows intermediaries to economize on showing and inspection costs. ${ }^{6}$

\footnotetext{
${ }^{5}$ There are a large literature of frictional matching with vertically differentiated persistent types (e.g. Burdett and Coles 1997, Smith and Shimer 2000). The informational inefficiency identified here is also present there.

${ }^{6}$ Informational externalities in frictional matching markets without intermediaries underlies the
} 
Another strand of literature on intermediaries argue that intermediaries emerge because they can help mitigate bilateral contracting problems which arise from the search environment, such as moral hazard (Diamond 1984), and adverse selection (Biglaiser 1993, Li 1998). For example, Diamond (1984) argues that by aggregating borrowers, financial intermediaries can reduce the variance of its portfolio payoff, reducing the cost of monitoring, and thus mitigate the incentive problems between borrowers and lenders. Biglaiser (1993) and Li (1998) show that the emergence of intermediaries can improve social welfare in markets with adverse selection if intermediaries have a reputation concern and a lower monitoring cost due to inventories which are larger than those carried by individual buyers. Similar to these papers, the advantage of our intermediaries also comes from larger inventories. Different from these papers, however, information is symmetric between trading partners in our model: neither the seller nor the buyer knows the matching value before inspection and they both know it after inspection.

Finally, there is also a sizeable literature on the price-setting intermediaries, such as dealers and market makers, in search markets. For example, Spulber (1996) studies an equilibrium search model with three types of agents: consumers, producers and middlemen (dealers). In his model, consumers and producers cannot trade directly with each other. Instead all trades have to be intermediated by the middlemen who post bid and ask prices. He shows that, the bid and ask prices converge to Walrasian equilibrium prices as the discount rate goes to zero, and approach monopoly prices as the discount rate increases. Rust and Hall (2003) introduce a monopolist market maker into Spulber (1996), and investigate when the market maker can survive and improve welfare. Yavas (1992) compares market makers and match makers in a one-period bilateral search model of intermediaries. In his model, it takes time and effort for individual participants to find a match, while market makers can trade immediately by posting bid and ask prices, and match makers can provide matching service to improve the matching probabilities of individual participants. None of these papers concerns the type of information externalities that we focus on.

social learning literature (see a survey by Bikhchandani, Hirshleifer, and Welch, 1998). But to our best knowledge, the role of intermediaries in internalizing information externalities through learning and inventory management has not been explored. 


\section{Search without Brokers}

To aid exposition, we present the model in the familiar housing market setting. Time is discrete with a period length $\Delta$ which is assumed to be small. ${ }^{7}$ All participants discount the future with a common discount rate $r$. Following the standard twosided search literature, we assume that two parties, buyers and sellers, simultaneously search for trading opportunities in the market. Each seller has one house for sale, and each buyer wants to buy one house. Buyers and sellers in the market are matched according to a random matching technology. Specifically, for a given period, if there are $B$ buyers and $S$ sellers in the market, then $M(B, S) \Delta$ buyers will randomly match with the same number of sellers. The matching function $M(B, S)$ is assumed to be increasing in both arguments and has constant return to scale. We use $\theta=B / S$ to denote the market tightness and use $m(\theta)$ to denote the arrival rate of match for a seller:

$$
m(\theta) \equiv M(B, S) / S .
$$

Then, in each period, a seller randomly meets a buyer with probability

$$
\frac{M(B, S) \Delta}{S}=m(\theta) \Delta,
$$

and a buyer meets a seller with probability

$$
\frac{M(B, S) \Delta}{B}=\frac{m(\theta) \Delta}{\theta} .
$$

There are $n$ types of buyers and sellers, with equal fraction of each type in the population. When a randomly chosen buyer meets a randomly chosen seller, the value of the match is either 1 or 0 . If the buyer's type (preference) matches the type of the house for sale, the value of the house to the buyer is 1 . Otherwise, the house has value 0 to the buyer. Before the buyer sees the house, both the buyer and the seller do not know the match value which can be found out only through costly house inspection. Every time a buyer inspects a house, the seller has to pay a showing cost $c_{s}$ and the buyer has to pay an inspection cost $c_{b}$.

If the seller has the type of the house that the buyer wants to buy and they are able to negotiate a sale, both parties leave the market permanently; otherwise, both of them will return to the market. We assume that there is an incoming flow of new buyers and new sellers such that the stocks and distributions of buyers and sellers do not change over time.

\footnotetext{
${ }^{7}$ As standard in the literature, the "small $\Delta$ " assumption allows us to use Poisson arrival process to approximate the discrete arrival probabilities.
} 
The goal of the paper is to investigate the role of search intermediaries in internalizing information externalities by reducing discrete search costs. In order to tease out intermediaries' role in reducing discrete search costs, we will primarily focus on the limit (steady-state) equilibrium when $r$ approaches $0 .{ }^{8}$ Note that it is sensible to focus on the limit equilibrium with $r=0$ only if we can prove the existence of a sequence of equilibria with $r>0$ that converge to the limit equilibrium. In Appendix A, we use Nash bargaining as an example of bargaining protocols to illustrate how to construct such a sequence both for search without brokers and for search with seller brokers.

\subsection{Equilibrium Welfare}

The continuation payoff $V$ for a seller who remains in the market at the end of period $\Delta$, when $\Delta$ is small, is given by

$$
V=\frac{1}{1+r \Delta}\left[m(\theta) \Delta\left(-c_{s}+\frac{1}{n} p\right)+\left(1-\frac{1}{n} m(\theta) \Delta\right) V\right] .
$$

To understand the formula, note that if the seller randomly meets a buyer next period (which happens with probability $m(\theta) \Delta$ ), she incurs a showing cost $c_{s}$ to show the house to the buyer, and if after costly inspection the buyer likes the house (which happens with probability $1 / n$ ) she sells the house at a negotiated price $p$; if the seller does not meet any buyer or if the seller meets a buyer but the match value turns out to be 0 after costly inspection, the seller remains in the market and receives continuation value $V$, which happens with probability $\left(1-\frac{1}{n} m(\theta) \Delta\right)$.

Similarly, the continuation payoff $U$ for a buyer who remains in the market at the end of period $\Delta$, when $\Delta$ is small, is given by

$$
U=\frac{1}{1+r \Delta}\left[\frac{m(\theta)}{\theta} \Delta\left(-c_{b}+\frac{1}{n}(1-p)\right)+\left(1-\frac{1}{n} \frac{m(\theta)}{\theta} \Delta\right) U\right] .
$$

If the buyer randomly meets a seller next period (which happens with probability $m(\theta) \Delta / \theta)$, he incurs an inspection cost $c_{b}$ to inspect the house, and if he likes the house (which happens with probability $1 / n$ ) he will buy the house at the negotiated price $p$. If the buyer does not meet any seller, or if the buyer meets a seller but the match value turns out to be 0 after costly inspection, the buyer remains in the market and receives $U$, which happens with probability $\left(1-\frac{1}{n} \frac{m(\theta)}{\theta} \Delta\right)$.

The price $p$ is negotiated by the two trading parties. It potentially depends on the discount rate $r$ and market conditions such as $\theta$ and $m(\theta)$. Different bargaining

\footnotetext{
${ }^{8}$ The sequential search literature worries about delay cost and is unconcerned with inspection and showing costs (e.g. Rogerson, Shimer and Wright 2005). A notable exception is Atakan (2006).
} 
protocols may result in different transaction prices, but the total social welfare is independent of prices. Since we are primarily concerned about the total welfare implication of search intermediaries, we do not assume a particular bargaining protocol. Instead, we only impose a weak requirement that under the transaction price both trading parties are willing to participate in the market, that is, a feasible price must in the core for each meeting.

We complete the model by imposing a free entry condition for sellers. Let $F$ be the cost to a home builder to build a house. The free entry of sellers implies $V=F$. In order for the market to exist, we assume throughout of the paper that

$$
1-n c_{b}-n c_{s}>F
$$

Definition 1 A steady-state search equilibrium without intermediaries is defined by the stocks of market participants $(B, S)$, continuation payoffs $(U, V)$, and market price p such that (a) seller and buyers behave optimally so (1) and (2) hold; (b) price $p$ is feasible; and (c) free entry condition $V=F$ holds.

We are primarily interested in the limit equilibrium with $r \rightarrow 0$ where delay cost is negligible. We derive all our equilibrium continuation values for general $r$, and then take the limit. ${ }^{9}$ It is straightforward to derive $U$ and $V$ from (1) and (2), and take $r \rightarrow 0$ to obtain the limit continuation value $U^{*}$ and $V^{*}$ as:

$$
\begin{aligned}
V^{*} & =\lim _{r \rightarrow 0} \frac{p-n c_{s}}{1+n r /(m(\theta))}=p^{*}-n c_{s}, \\
U^{*} & =\lim _{r \rightarrow 0} \frac{1-p-n c_{b}}{1+n r \theta /(m(\theta))}=1-p^{*}-n c_{b},
\end{aligned}
$$

It follows from the free entry condition $V=F$ that the limit price $p^{*}$ must be

$$
p^{*}=F+n c_{s}
$$

Therefore, the total social welfare for a pair of seller and buyer is

$$
U^{*}+V^{*}=1-n c_{b}-n c_{s} .
$$

This will serve as the welfare benchmark for our subsequent analysis of search with brokers. Intuitively, there are $n$ type of goods, so when a pair of buyer and seller meets, the probability of having a successful match is $1 / n$. This implies that the expected number of inspections for producing a successful match is $n$. Hence, the total welfare $\left(U^{*}+V^{*}\right)$ for a pair of buyer and seller is $1-n c_{b}-n c_{s}$.

\footnotetext{
${ }^{9}$ The derivation is standard in the frictional search literature. See, for example, Rogerson, Shimer and Wright (2005).
} 


\section{Search with Seller Brokers}

Again suppose there are $n$ types of houses and buyers with equal proportion. We add seller-brokers (henceforth brokers) who first contact sellers to seek exclusive representation and then sell houses on the sellers' behalf to buyers. For simplicity and tractability, we assume that there are two physically distinct markets where trade

occurs. In the sellers' market, brokers search for sellers to represent them. In the buyers' market, brokers meet buyers to arrange transactions on the sellers' behalf. Buyers, sellers and brokers can visit either market at any time. Each participant can visit only one market at a time. We say a broker completes a "transaction" after he picks up a seller representation in the sellers' market and then successfully sells the house on the seller's behalf to a buyer in the buyers' market.

For technical tractability, we assume that a broker can represent at most two sellers. Under this assumption, there are only four possible types of brokers: brokers without a house, brokers with one house, brokers with two identical houses, and brokers with two distinct houses. Similarly, there are only four possible sellers: sellers without brokers, or sellers contracted to one of three brokers with houses. In other words, this small capacity assumption reduces the number of possible broker types and seller types we need to track in equilibrium. If we increase the capacity of brokers, the number of possible broker types and seller types grows exponentially, substantially complicating the analysis without adding much insights. Since a larger capacity will only strengthen the advantage of intermediated trade over direct trade, our small capacity assumption will lead to most stringent conditions for search intermediaries to arise and improve welfare.

We assume for now that a broker wants to have two different types of houses in her inventory before going to the buyers' market. Upon selling one house, the broker will return to the sellers' market to find another seller to represent whose house is different from the one that the broker has already represented. After the broker has obtained representation of two different types of houses, the broker returns to the buyers' market and so on. We assume that, after a seller signs up a seller broker, all future showing costs are incurred by the broker rather than the seller, except that, when the broker finds a perfect match for the house, the owner of the house (the seller) needs to incur one last showing cost to the buyer (who then incurs the corresponding inspection cost) to complete the trade. The last showing (inspection) cost captures potential closing or bargaining cost that the seller (buyer) incurs in order to complete the deal.

The assumption of the last showing cost also has a technical role. As we previously mentioned, in order to justify our focus of the limit equilibrium, we need to prove 
the existence of a sequence of equilibria with $r>0$ that converge to the limit one. We construct such a sequence by assuming Nash bargaining protocol in Appendix A. With Nash bargaining, if the seller does not need to incur the last showing cost, in the limit with $r \rightarrow 0$, the seller will hold up the broker because, while the seller incurs no cost to bypass the current buyer and find the next suitable buyer, it is costly for the broker to do so. As a result, the limit of the sequence of equilibria under Nash bargaining may not exist. The last showing cost can help avoid this hold-up problem. Since the additional showing cost cuts in the advantage of search with brokers, this again will lead to more stringent conditions for welfare improving brokers to exist.

We assume that brokers have no cost advantage over sellers and buyers. First, when a seller and a broker randomly meet in the sellers' market, a costly inspection is carried out. After the seller incurs a showing cost $c_{s}$ and the broker incurs an inspection cost $c_{b}$, the broker learns the type of the house. Second, when a buyer and a broker randomly meet in the buyers' market, the broker incurs a showing cost to show a randomly chosen house to the buyer who incurs an inspection cost to see the house. After costly inspection, the buyer figures out if he likes the house, and the broker also learns the buyer's preferred type of house. In Appendix B, we show that our analysis remains valid qualitatively if we relax the assumption of perfect communication.

We also assume that brokers have no matching advantage over sellers and buyers: the matching technology between brokers and sellers (or buyers) is the same as the one in the market without intermediaries. ${ }^{10}$ Let $A_{s}$ denote the number of brokers with one house in the sellers' market, and $A_{b}$ denote the number of brokers with two houses in the buyers' market. Let $\theta_{s}$ denote the market tightness of the sellers' market where brokers pick up houses: $\theta_{s}=A_{s} / S$, and let $m\left(\theta_{s}\right)$ denote the the arrival rate of a match for a seller in the sellers' market: $m\left(\theta_{s}\right) \equiv M\left(A_{s}, S\right) / S=M\left(\theta_{s}, 1\right)$. Then in the sellers' market, The probability for a seller to meet a broker is $m\left(\theta_{s}\right) \Delta$, and the probability for a broker to meet a seller is $m\left(\theta_{s}\right) \Delta / \theta_{s}$. Similarly, define $\theta_{b}=B / A_{b}$ as the market tightness of the buyers' market where brokers sell houses to buyers, and let $m\left(\theta_{b}\right)$ denote the the arrival rate of a match for a broker in the buyers' market: $m\left(\theta_{b}\right) \equiv M\left(B, A_{b}\right) / A_{b}=M\left(\theta_{b}, 1\right)$. Then in the buyers' market, the probability for a broker to randomly meet a buyer is $m\left(\theta_{b}\right) \Delta$, and the probability for a buyer to meet a broker is $m\left(\theta_{b}\right) \Delta / \theta_{b}$. To simplify notation, in what follows we write $m_{s}=m\left(\theta_{s}\right)$

\footnotetext{
${ }^{10}$ In practice, however, it is often easier for home buyers and sellers to contact brokers than to contact each other. This gives an exogenous advantage to brokers in meeting buyers and sellers. We want to dispense with this advantage which has already been studied in Rubinstein and Wolinsky (1987). Thus we do not give brokers an exogenous faster arrival rate of clients to focus on the inventory advantage.
} 
and $m_{b}=m\left(\theta_{b}\right)$.

We also assume for now that (i) buyers and sellers will not trade directly, (ii) sellers will not pretend to be brokers with two houses, and (iii) buyers will not pretend to be brokers with one house. We also assume earlier that (iv) a broker wants to have two different types of houses in his inventory before going to the buyers' market. Later we will specify conditions under which, in the search equilibrium with brokers, these incentive conditions (i)-(iv) are indeed satisfied. That is, we first characterize a limit equilibrium where brokers are active and then we will derive conditions for equilibrium existence.

\subsection{Equilibrium Welfare}

Now we want to derive the continuation values for a seller, a broker with one house, a broker with two distinct houses, and a buyer. A seller in the market could be in one of the following three possible states: not contracted with a broker, contracted with a broker who has another client, and contracted with a broker who has no other client.

First, the functional equation for $V$, the continuation value of a seller without a broker at the end of period $\Delta$, is

$$
V=\frac{1}{1+r \Delta}\left[m_{s} \Delta\left(-c_{s}+\frac{n-1}{n}\left(V_{a}-\phi\right)\right)+\left(1-m_{s} \Delta \frac{n-1}{n}\right) V\right] .
$$

Here $m_{s} \Delta$ is the probability for a seller to meet a broker in the sellers' market. Once they meet, the seller incurs cost $c_{s}$ to show the house to the broker who incurs a cost $c_{b}$. With probability $(n-1) / n$, the house type is different from the type of the other house that the broker already represents. In this case, the seller pays a commission $\phi$ to the broker who will show the house on the seller's behalf. Otherwise, the seller continues to search for a broker in the sellers' market.

Second, the functional equation for $V_{a}$, the continuation value of a seller contracted with a broker who has another client, is

$$
V_{a}=\frac{1}{1+r \Delta}\left[m_{b} \Delta\left(\frac{1}{n}\left(p-c_{s}\right)+\frac{1}{n} V_{b}\right)+\left(1-m_{b} \Delta \frac{2}{n}\right) V_{a}\right] .
$$

The seller's broker meets a buyer in the buyers' market with probability $m_{b} \Delta$. Once the broker and the buyer meet, the broker incurs a cost $c_{s}$ and the buyer incurs a cost $c_{b}$ through a costly inspection to find out the buyer's preference. If the buyer's type is a perfect match with one of the broker's house (which happens with probability $2 / n$, with probability $1 / n$ for each seller), the broker asks the owner of the house to show it to the buyer. Consider seller 1 who is contracted with the broker. If her house 
matches the buyer preference (with probability $1 / n$ ), she incurs the final showing cost $c_{s}$ to show her house to the buyer and obtains price $p$; if the other house of the broker matches the buyer preference (with probability $1 / n$ ), then her broker has to go back to the sellers' market to pick up another house, that is, her continuation value becomes $V_{b}$ which is defined below. If none of the above happens (with probability $\left.1-m_{b} \Delta \frac{2}{n}\right)$, the seller retains continuation value $V_{a}$.

Third, the functional equation for $V_{b}$, the continuation value of a seller who is contracted with a broker but her broker has no other client and thus has to return to the sellers' market to pick up another seller before selling her house in the buyers' market, is

$$
V_{b}=\frac{1}{1+r \Delta}\left[\frac{m_{s}}{\theta_{s}} \Delta \frac{n-1}{n} V_{a}+\left(1-\frac{m_{s}}{\theta_{s}} \Delta \frac{n-1}{n}\right) V_{b}\right] .
$$

The term $\frac{m_{s}}{\theta_{s}} \Delta$ is the probability that the broker meets another seller in the sellers' market and $\frac{n-1}{n}$ is the probability that the second house is different from the type of the first house that the broker already represents. That is, $\frac{m_{s}}{\theta_{s}} \Delta \frac{n-1}{n}$ is the probability for the broker to successfully pick up another seller, and in this case the continuation value for the seller becomes $V_{a}$. Otherwise, the broker has to continue search in the sellers' market for another period.

Let $W_{1}$ and $W_{2}$ be the continuation value of a broker with one house and a broker with two houses at the end of period $\Delta$, respectively. Then the functional equation for a broker with one house is

$$
W_{1}=\frac{1}{1+r \Delta}\left[\frac{m_{s}}{\theta_{s}} \Delta\left(-c_{b}+\frac{n-1}{n}\left(W_{2}+\phi\right)\right)+\left(1-\frac{m_{s}}{\theta_{s}} \Delta \frac{n-1}{n}\right) W_{1}\right] .
$$

Here $\frac{m_{s}}{\theta_{s}} \Delta$ is the probability for a broker with one house to meet another seller in the sellers' market. Once they meet, the broker performs a costly inspection. With probability $\frac{n-1}{n}$, the second house type is different from the type of the first house represented by the broker. In this case, the broker will agree to represent the second house with commission $\phi$, and the continuation value for the broker becomes $W_{2}$. Otherwise the broker has to continue search in the sellers' market.

The functional equation for a broker with two houses is

$$
W_{2}=\frac{1}{1+r \Delta}\left[m_{b} \Delta\left(-c_{s}+\frac{2}{n}\left(W_{1}-\frac{1}{2} c_{s}\right)\right)+\left(1-m_{b} \Delta \frac{2}{n}\right) W_{2}\right] .
$$

The term $m_{b} \Delta$ is the probability for the broker to meet a buyer in the buyers' market. Upon a meeting, the broker shows a first house to the buyer at a cost of $c_{s}$. After showing the house, the broker will learn whether the buyer likes the first or second house, or other types of houses. If the buyer likes the first house (with probability $1 / n)$, the buyer will next deal with the seller to buy the house. If the broker learns 
that the buyer likes the second house (with probability $1 / n$ ), he will incur another showing $\operatorname{cost} c_{s}$ to show the second house to the buyer. After seeing the second house, the buyer will deal with the seller to buy the house. After showing the first house, if the broker learns that the buyer does not like either house, they separate and the broker has to continue search in the buyers' market for another period.

Finally, let $U$ be the continuation value of a buyer who remains in the market at the end of period $\Delta$. Then we have

$$
U=\frac{1}{1+r \Delta}\left[\frac{m_{b}}{\theta_{b}} \Delta\left(-c_{b}+\frac{2}{n}\left(1-p-\frac{3}{2} c_{b}\right)\right)+\left(1-\frac{m_{b}}{\theta_{b}} \Delta \frac{2}{n}\right) U\right] .
$$

The term $\frac{m_{b}}{\theta_{b}} \Delta$ is the probability for a buyer to meet a broker with two houses in the buyers' market. Once a buyer meets a broker, the buyer incurs an inspection cost $c_{b}$ to see a house. If the first house fits (with probability $1 / n$ ), the buyer will incur another inspection cost to deal with the seller and buy the house for price $p$. If the first house does not fit and the second house fits (with probability $1 / n$ ), the buyer will incur another inspection cost to see the second house, and a further inspection cost to deal with the seller and buy the house for price $p$. If neither house fits, the buyer separates from the broker and continue to search in the buyers' market for another period.

As in the previous section, we do not specify the bargaining protocol that determines the transaction price $p$ and the commission $\phi$. We only require that the price and the commission are feasible in the following sense: the price $p$ or the commission $\phi$ is in the core for every meeting, and the expected profit for a broker from each transaction is zero as $r \rightarrow 0$.

In the steady state, the number of brokers picking up houses successfully in the sellers' market must be equal to the number of brokers selling houses successfully in the buyers' market. That is,

$$
A_{s} \frac{n-1}{n} \frac{m_{s}}{\theta_{s}}=A_{b} \frac{2}{n} m_{b}
$$

Finally, we impose free entry conditions to complete the model. First, with free entry of home builders, sellers must get the same reservation utility as home builders, that is, $V=F$. Second, we impose free entry condition for brokers. Let $L$ denote the broker's outside option. The broker without a client can go to the sellers' market to pick up a house by incurring cost $c_{b}$. But the continuation value for a broker with one client is $W_{1}$. Therefore, when $r \rightarrow 0$, we can write the free entry condition for the broker as:

$$
W_{1}^{*}=L+c_{b}-\phi
$$


Definition 2 A steady-state search equilibrium with brokers is defined by the stocks of market participants $(B, S)$, continuation payoffs $\left(V, V_{a}, V_{b}, W_{1}, W_{2}, U\right)$, commission $\phi$ and market price $p$ such that (a) all market participants behave optimally so that equations (6)-(11) hold; (b) the stationary condition (12) holds; (c) commission $\phi$ and price $p$ are feasible; (d) free entry conditions for sellers and brokers hold; and (f) incentive conditions (i)-(iv) are satisfied.

Again, as in the previous section, we derive all our equilibrium continuation values for general $r$, and then take the limit. It is straightforward to compute the continuation value $U$ and $V$ for a fixed $r$, and then take $r \rightarrow 0$ to obtain the limit continuation values:

$$
\begin{aligned}
U^{*} & =1-p^{*}-\frac{n+3}{2} c_{b}, \\
V^{*} & =p^{*}-\phi^{*}-\frac{2 n-1}{n-1} c_{s}
\end{aligned}
$$

where $p^{*}$ is the limit of transaction price $p$, and $\phi^{*}$ is the limit of the commission fee $\phi$.

Note that the limit commission fee $\phi^{*}$ must be such that the expected profit for a broker from each transaction is zero as $r \rightarrow 0$. Otherwise, brokers will make infinite total profits because they are infinitely lived. As can be verified using functional equations (9) and (10), in order to ensure the existence of the limit of $W_{1}$ and $W_{2}$, the limit commission fee $\phi^{*}$ must exactly cover the expected inspection costs and showing costs that a broker needs to incur in order to complete a trade, that is,

$$
\phi^{*}=\frac{n+1}{2} c_{s}+\frac{n}{n-1} c_{b} .
$$

To gather intuition, we recall that each transaction consists of a purchase and a sale. Notice that a broker needs to meet $n / 2$ buyers on average in order to find a buyer who will like one of the two houses, and the broker needs to meet $n /(n-1)$ sellers in order to re-stock a house. And when he finds a buyer who matches a house, the broker may still need to incur another showing cost with probability $1 / 2$. This gives us the right hand side of (13). It then follows from the free entry condition for the seller $V=F$ that the limit price must be

$$
p^{*}=F+\frac{n}{n-1} c_{b}+\left(\frac{2 n-1}{n-1}+\frac{n+1}{2}\right) c_{s}
$$

Since the brokers earn zero profit from each successful transaction, the total expected payoff of buyers and sellers coincide with the total social welfare. Therefore, 
in the limit search equilibrium with seller brokers, the total expected social welfare for a pair of seller and buyer

$$
U^{*}+V^{*}=1-\frac{n}{n-1}\left(c_{b}+c_{s}\right)-\frac{n+3}{2}\left(c_{b}+c_{s}\right)
$$

The intuition for (15) is the following. First, a successful transaction takes $\frac{n}{n-1}$ inspections on average in the sellers' market because a broker picks up a new seller with probability $\frac{n-1}{n}$. Second, a buyer needs to talk to $\frac{n}{2}$ brokers on average in order to find a good match because the probability that a buyer likes one of the two houses managed by a broker is $\frac{2}{n}$. Moreover, in case there is a match, the buyer needs to deal with the seller of the house one more time to verify the match. As a result, a successful transaction needs $\frac{n}{2}+1$ inspections in the buyers' market. Finally there is an expected $\frac{1}{2}$ extra inspection when a broker meets a buyer because conditional on a match, the second house, rather than the first, fits the buyer with probability $1 / 2$. Therefore, the total expected search cost for a successful transaction is $\frac{n}{n-1}\left(c_{b}+c_{s}\right)+\frac{n+3}{2}\left(c_{b}+c_{s}\right)$. The expression (15) then follows from the fact that the value of a good match is 1 .

By comparing the social welfare with brokers (15) and without brokers (5), we obtain the welfare improvement (for a pair of buyer and seller) due to brokers:

$$
\frac{n^{2}-6 n+3}{2(n-1)}\left(c_{b}+c_{s}\right) \text {. }
$$

Therefore, the introduction of brokers improves social welfare as long as $n \geq 6$. Intuitively, introducing brokers into the market adds two extra rounds of screening costs from using brokers. In order to recover these additional screening costs, the degree of heterogeneity must be sufficiently large such that buyers can avoid inspecting houses that they will reject.

\subsection{Incentive Conditions}

In order to fully characterize the equilibrium, we need to find conditions under which the following incentive conditions hold: (i) buyers and sellers will not trade directly, (ii) sellers will not directly go to the buyers' market, (iii) buyers will not directly go to the sellers' market, and (iv) brokers will not go to the buyers' market unless they have picked up two seller representations with two different types of houses.

Recall that, when $n \geq 6$, the joint payoffs of buyers and sellers are higher in dealing with brokers compared to trading directly. By trading directly either the seller or the buyer will be worse off and thus at least one of the two parties will refuse to trade directly. Therefore, incentive condition (i) is satisfied if $n \geq 6$. It remains to find conditions for (ii)-(iv). 
Let us first consider the incentive of sellers. A seller can pretend to be a broker with two houses and approach buyers in the buyers' market. If a buyer rejects the house on offer, the seller can say that the other house in her phantom inventory does not fit the buyer's preference either. When a seller goes to the buyers' market directly by pretending to be a broker, she saves the commission but incurs an increase in expected showing cost equal to $n c_{s}-\left(\frac{n}{n-1}+1\right) c_{s}$, where the first term is the expected showing cost without a broker and the second term is the expected showing cost with a broker. Therefore, a seller will not pretend to be a broker if

$$
\phi^{*}=\frac{n+1}{2} c_{s}+\frac{n}{n-1} c_{b} \leq n c_{s}-\left(\frac{n}{n-1}+1\right) c_{s}
$$

which is equivalent to

$$
\frac{c_{b}}{c_{s}} \leq \frac{n^{2}-6 n+3}{2 n}
$$

Next we consider the incentives of buyers. A buyer can pretend to be a broker with one house and buy directly from a seller at price $\left(p^{*}-\phi^{*}\right)$ in the following way. If the house fits the buyer's preference, the buyer pays $\left(p^{*}-\phi^{*}\right)$ to the seller who will happily accept. If the house does not fit, the buyer tells the seller that the house coincides what he already has. When a buyer goes to the sellers' market directly by pretending to be a broker, he gains from price reduction of $\phi$ but incurs an increase in expected inspection cost equal to $n c_{b}-\frac{n}{2}\left(1+\frac{2}{n}\left(1+\frac{1}{2}\right)\right) c_{b}$. The first term is the expected inspection cost without a broker and the second term is the expected cost with a broker. Buyers will not enter the sellers' market directly if

$$
\phi^{*}=\frac{n+1}{2} c_{s}+\frac{n}{n-1} c_{b} \leq n c_{b}-\frac{n}{2}\left(1+\frac{2}{n}\left(1+\frac{1}{2}\right)\right) c_{b}
$$

That is

$$
\frac{c_{b}}{c_{s}} \geq \frac{n^{2}-1}{n^{2}-6 n+3}
$$

Finally, we consider the incentives of brokers. Although in principle the broker can deviate for any number of transactions, by the unimprovability criterion of dynamic programming, it is sufficient to show that the broker cannot gain from deviation for one transaction. We first find conditions under which a broker with one house will not immediately go to the buyers' market to look for a buyer. Since a broker's deviation cannot affect market prices, we only need to compare expected cost to complete a transaction. Consider a broker with one house. If he picks up another house of a different type before he goes to the buyers' market, his additional expected cost to complete a transaction is $\frac{n}{n-1} c_{b}+\frac{n+1}{2} c_{s}$. If a broker with one house goes to the buyers' market directly, his expected cost to completing a transaction is $n c_{s}$. Therefore, a 
broker with one house will not pretend to be a broker with two houses and search buyers directly if

$$
\frac{n}{n-1} c_{b}+\frac{n+1}{2} c_{s} \leq n c_{s}
$$

which reduces to

$$
\frac{c_{b}}{c_{s}} \leq \frac{n^{2}-2 n+1}{2 n}
$$

Next, we look for conditions to insure that a broker will not go to the buyers' market with two identical houses. Suppose a broker with one house meets a seller to pick up a second house and finds out that it is a duplicate of the first. This broker's expected cost of completing a transaction is no different from that of a broker with one house. We have shown earlier that under condition (19), a broker with one house wants to find another house which is not the duplicate of the first. Since his inspection of the duplicate second house is already sunk, there is no additional cost to discarding it and searching for a different house compared with a broker with one house. Therefore, as long as condition (19) holds, the broker will reject the seller and continue search in the sellers' market rather than go to the buyers' market with two identical houses.

\subsection{Summary}

It is easy to see that the broker's incentive condition (19) is implied by the seller's incentive condition (17) for all $n \geq 2$. Therefore, all parties' incentive conditions are satisfied if

$$
\frac{n^{2}-1}{n^{2}-6 n+3} \leq \frac{c_{b}}{c_{s}} \leq \frac{n^{2}-6 n+3}{2 n}
$$

We can plot condition (20) as follows:

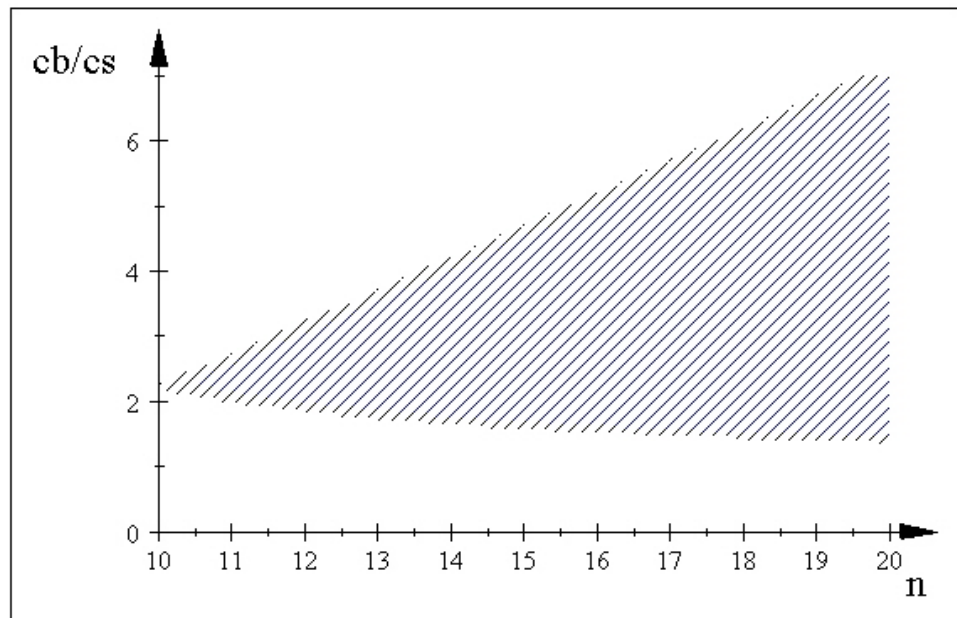


Notice that the set of cost ratio $c_{b} / c_{s}$ that satisfies above constraints is non-empty as long as $n \geq 11$. Moreover, as the degree of heterogeneity $n$ increases, the set defined by (20) expands. However, the welfare improving seller brokers exist only if $c_{b}>c_{s}$.

The rationale for seller brokers is to hold inventory in order to economize on the buyers' expected inspection costs. Thus it should not be surprising that such equilibria exists only when inspection cost exceeds showing costs (see Section 5 for analysis of buyer brokers when the reverse is true). The following proposition summarizes the main result of this section.

Proposition 1 Suppose that broker learning is perfect. A search equilibrium with seller-brokers exists and improves social welfare if condition (20) holds.

To conclude this section, we note that if brokers need a license to operate, then neither buyers nor sellers can pretend to be brokers. If this is the case, the only relevant incentive constraints are those for brokers, and the constraint that buyers and sellers do not trade directly. Therefore, brokers exist and improve welfare if $n \geq 6$ and (19) holds.

\section{The Case of Buyer Brokers}

We note that in the previous section, the search equilibrium with seller brokers may not exist if $c_{b}<c_{s}$. Can other types of intermediaries exist if $c_{b}<c_{s}$ ? This section briefly illustrates how we can adapt our previous analysis to study buyer brokers who represent buyers in their search for goods.

Again suppose there are $n$ types of goods and buyers with equal proportion. New buyers and sellers, drawn uniformly from the $n$ types, arrive at the market sequentially. Instead of seller brokers, consider a buyer broker (henceforth broker) who first contacts buyers in the buyers' market. When a broker meets a buyer, the broker incurs a show cost $c_{s}$, the buyer pays a inspection cost $c_{b}$, and the broker finds out the buyer's preference. If they agree on the commission $\phi$ and representation, then the broker will represent the buyer in the sellers' market and receive $\phi$. Once a broker meets with a seller, the seller pays a show cost $c_{s}$ to show his good and the broker pays $c_{b}$ to inspect the good. After the broker finds a suitable good for her client to buy, the buyer will inspect the good and negotiate to buy the good from the seller. The buyer and seller leave the market permanently after trade. Assume that a broker can represent at most two buyers.

Similar to the case of seller brokers, we assume for now that (i) buyers and sellers will not trade directly, (ii) sellers will not pretend to be brokers with one client, (iii) 
buyers will not pretend to be brokers with two clients, and (iv) brokers will not go to the sellers' market unless they have already contracted with two different buyers. At the end of this section, we will specify conditions under which the incentive conditions (i)-(iv) hold.

With abuse of notation, we let $A_{s}$ denote the number of brokers with two buyers, and $A_{b}$ denote the number of brokers with one buyer. Define $\theta_{s}$ the market tightness of the sellers' market where brokers try to find the right sellers to their clients: $\theta_{s}=A_{s} / S$. Similarly, define $\theta_{b}$ the market tightness of the buyers' market where brokers find buyers: $\theta_{b}=B / A_{b}$. We assume that the matching technology between brokers and sellers (or buyers) is the same as the one in markets without intermediary. Therefore, with abuse of notation, in the sellers' market, we denote the arrival rate of a match for a seller by $m\left(\theta_{s}\right) \equiv M\left(\theta_{s}, 1\right)$, and the arrival rate of a match for a broker by $m\left(\theta_{s}\right) / \theta_{s}$. Similarly, in the buyers' market, the arrival rate of a match for a broker is $m\left(\theta_{b}\right)$ and the arrival rate of a match for a buyer is $m\left(\theta_{b}\right) / \theta_{b}$.

Similar to the case of seller brokers, in the steady state, the number of brokers picking up buyers successfully must be equal to the number of brokers who find the right good for one of their clients:

$$
A_{s} \frac{2}{n} \frac{m\left(\theta_{s}\right)}{\theta_{s}}=A_{b} \frac{n-1}{n} m\left(\theta_{b}\right) .
$$

To complete the model, we impose the free entry condition for sellers $(V=F)$ and for brokers $\left(W_{1}^{*}=L+c_{s}-\phi^{*}\right)$. The search equilibrium with brokers can be defined analogously to the one with seller brokers.

As in the case of seller brokers, we can write down the value functions for sellers, buyers and brokers. We can solve these functional equations and obtain the following limit solution (see Appendix C for details):

$$
\begin{aligned}
V^{*} & =p^{*}-\frac{n+2}{2} c_{s}, \\
U^{*} & =1-p^{*}-\phi^{*}-\frac{2 n-1}{n-1} c_{b},
\end{aligned}
$$

with the limit commission fee $\phi^{*}$

$$
\phi^{*}=\frac{n}{n-1} c_{s}+\frac{n}{2} c_{b}
$$

and the limit price $p^{*}$

$$
p^{*}=F+\frac{n+2}{2} c_{s}
$$

Therefore, the total social welfare is

$$
U^{*}+V^{*}=1-\frac{n+2}{2}\left(c_{s}+c_{b}\right)-\frac{n}{n-1}\left(c_{s}+c_{b}\right)
$$


Finally, we verify that all parties' incentive conditions are satisfied (see Appendix C for details) if $n \geq 5$ and

$$
\frac{2 n}{n^{2}-5 n+2} \leq \frac{c_{b}}{c_{s}} \leq \frac{n-3}{n-1}
$$

The set of cost ratio $c_{b} / c_{s}$ that satisfies above constraints is non-empty as long as $n \geq 8$. We can plot condition (25) as follows:

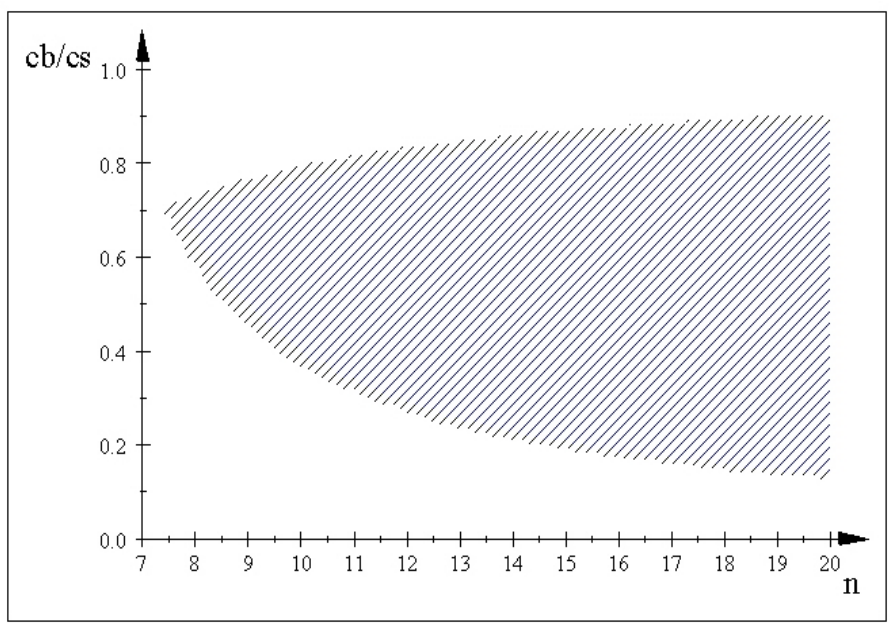

It is clear from (25) and from the above graph that, as $n$ increases, the set defined by (25) expands.

Proposition 2 Suppose that broker learning is perfect. A search equilibrium with buyer-brokers exists and improves social welfare if condition (25) holds.

Again broker licensing may relax our incentive constraints so that our welfare improving brokerage can exist under weaker conditions. Suppose a buyer broker needs a license to operate, so that neither buyers nor sellers can pretend to be broker. In this case, the only relevant incentive constraints are those for brokers, and the constraint that buyers and sellers do not trade directly, namely (39) in Appendix C and the constraint $n \geq 5$.

It is worth noting that welfare improving buyer brokers can exist only if $c_{b}$ is less than $c_{s}$, while welfare improving seller brokers can exist only if the reverse is true. Therefore, the parameter space for seller brokers to exist and for buyer brokers to exist is naturally separated. To understand the underlying rationale for this separation, let us compare the limit commission fees for the two types of brokers:

$$
\begin{array}{ll}
\text { seller brokers: } & \frac{n+1}{2} c_{s}+\frac{n}{n-1} c_{b}, \\
\text { buyer brokers: } & \frac{n}{n-1} c_{s}+\frac{n}{2} c_{b} .
\end{array}
$$


In the search equilibrium with seller brokers, when $n$ is large, the size of commission is primarily determined by the size of show $\operatorname{cost} c_{s}$. In contrast, in the search equilibrium with buyer brokers, the size of commission is primarily determined by the size of inspection cost $c_{b}$. The main constraint for the existence of seller brokers or buyer brokers is that either buyers or sellers may not want to deal with intermediaries if the commission fee is too high. Therefore, whether seller brokers or buyer brokers will exist depends on which intermediary can operate with a lower intermediation charges. As a result, intermediation through seller brokers is less prone for deviation by market participants when $c_{b}>c_{s}$, whereas intermediation through buyer brokers is less prone for deviation when $c_{b}<c_{s}$.

\section{Concluding Remarks}

We use a stylized model to illustrate how search intermediaries can internalize information externalities arising in the two-sided frictional matching market. In the text, we assume a broker learns the preference of a buyer perfectly once they incur search costs. Appendix B generalizes our results qualitatively to the setting where the communication between a broker and a buyer is noisy.

In our model, the broker is either a seller broker or a buyer broker, and we do not allow seller brokers and buyer brokers to coexist. It will be interesting to consider a model where both sellers and buyers are brokered through agencies. We may also want to consider directed search rather than random sequential search. Consider a housing market in which there are neighborhoods and houses. Real estate agents specialize by neighborhoods. Buyers have to choose a neighborhood and a house

within the neighborhood. Neighborhoods are fixed geographically. So a buyer can choose to search within specific neighborhoods. In this case, we have a hybrid model of directed and sequential search.

\section{Appendix A: Nash Bargaining}

This appendix illustrates how one can construct a sequence of equilibria with $r>0$ that converge to the limit equilibrium we focus on in the text. Here we assume the bargaining protocol is Nash Bargaining.

We first consider the case without brokers. To avoid the hold-up problem and a non-existence of equilibrium with trade when $r$ approaches zero, we assume that the 
price $p$ is negotiated before inspection, ${ }^{11}$

$$
p=\arg \max _{p^{\prime}}\left[-c_{b}+\frac{1}{n}\left(1-p^{\prime}\right)+\frac{n-1}{n} U-U\right]\left[-c_{s}+\frac{1}{n} p^{\prime}+\frac{n-1}{n} V-V\right] .
$$

To understand the formula, note that if a buyer agrees to price $p^{\prime}$ and proceeds to inspect the house by incurring cost $c_{b}$, with probability $1 / n$ he likes the house and obtains net payoff $\left(1-p^{\prime}\right)$, and with probability $(n-1) / n$ the house does not match his preference, so he returns to the market. If a buyer does not agree, he has to return to the market with continuation value $U$. The intuition for the seller's part is similar. It follows that the transaction price $p$ is set at

$$
p=\frac{1}{2}\left(1+V-U+n c_{s}-n c_{b}\right) .
$$

The two functional equations (1) and (2) can be rearranged into

$$
\begin{aligned}
& r V=m(\theta)\left[-c_{s}+\frac{1}{n}(t-V)\right], \\
& r U=\frac{m(\theta)}{\theta}\left[-c_{b}+\frac{1}{n}(1-t-U)\right] .
\end{aligned}
$$

Substituting $t$ into the functional equations, we can solve $U$ and $V$ as

$$
\begin{aligned}
U & =\frac{m(\theta)}{m(\theta)+\theta m(\theta)+2 n \theta r}\left(1-n c_{b}-n c_{s}\right), \\
V & =\frac{\theta m(\theta)}{m(\theta)+\theta m(\theta)+2 n \theta r}\left(1-n c_{b}-n c_{s}\right) .
\end{aligned}
$$

Letting $r \rightarrow 0$, we have

$$
\begin{aligned}
U^{*} & =\frac{1}{1+\theta}\left(1-n c_{b}-n c_{s}\right), \\
V^{*} & =\frac{\theta}{1+\theta}\left(1-n c_{b}-n c_{s}\right) .
\end{aligned}
$$

Intuitively, the social surplus is shared according to market tightness $\theta$ : the seller gets a larger share if the market condition is more favorable to the seller (i.e., a higher $\theta$ ). The market tightness $\theta$ is recovered from equation (29) and the free entry condition $V=K$.

Next consider the case with seller brokers. Suppose the commission $\phi$ between a seller and a broker is established by Nash bargaining before the broker inspects the

\footnotetext{
${ }^{11}$ Both the hold-up problem in this class of models (see Spulber 2009) and the non-existence problem of the equilibrium with trade as $r$ approaches zero are well known (e.g. Camera and Delacroix 2003). Dealing with these problems detract from our concern here.
} 
house:

$$
\begin{aligned}
\phi & =\arg \max _{p^{\prime}}\left(-c_{b}+\frac{n-1}{n}\left(p^{\prime}+W_{2}\right)+\frac{1}{n} W_{1}-W_{1}\right)\left(-c_{s}+\frac{n-1}{n}\left(-p^{\prime}+V_{a}\right)+\frac{1}{n} V-V\right) \\
& \Rightarrow \phi=\frac{1}{2}\left(V_{a}-V-W_{2}+W_{1}+\frac{n}{n-1}\left(c_{b}-c_{s}\right)\right)
\end{aligned}
$$

The interpretation of the objective is analogous to (26).

We assume that after the broker meets with the buyer, the broker first negotiates a price $p$ with the buyer on the sellers' behalf before performing costly inspections. Specifically, the transaction price $p$ between a seller and a buyer is determined by Nash bargaining as follows:

$$
p=\arg \max _{p^{\prime}}\left\{\begin{array}{c}
\left(\left[\frac{1}{n}\left(p^{\prime}-c_{s}\right)+\frac{1}{n} V_{b}+\frac{n-2}{n} V_{a}\right]-V_{a}\right) \\
\left(\left[-c_{b}+\frac{2}{n}\left(1-p^{\prime}-\frac{3}{2} c_{b}\right)+\frac{n-2}{n} U\right]-U\right)
\end{array}\right\} .
$$

From a seller's perspective, if she agrees to price $p^{\prime}$, with probability $1 / n$ her house may match the buyer's preference in which case she gets $\left(p^{\prime}-c_{s}\right)$, and with probability $1 / n$ the other house the broker is representing matches the buyer's preference in which case she gets $V_{b}$. If none of the two houses match the buyer's preference (which happens with probability $(n-2) / n)$, her continuation value will be $V_{a}$. If she does not agree to price $p^{\prime}$, she gets her outside option $V_{a}$. From a buyer's perspective, if he agrees to price $p$ and incurs cost $c_{b}$, with probability $1 / n$ he will find out that the first of the two houses matches his preference in which case he gets $\left(1-p^{\prime}-c_{b}\right)$, and with probability $1 / n$ the second house (the one the broker didn't show) of the two houses matches his preference in which case he gets $\left(1-p^{\prime}-2 c_{b}\right)$. With probability $(n-2) / n$ neither house matches his preference and he obtains continuation value $U$. If he rejects price $p^{\prime}$, he gets outside option $U$.

Therefore, the price is given by

$$
p=\frac{1}{2}\left(1+2 V_{a}-V_{b}-U+c_{s}-\frac{n+3}{2} c_{b}\right) .
$$

Substitute $\phi$ and $p$ into the functional equations. We can show with some algebra that $V=\theta_{s} W_{1}$ and $V_{a}=\frac{1}{2} \theta_{b} U$. Taking $r \rightarrow 0$, we solve $U^{*}$ and $V^{*}$ in the limit equilibrium: ${ }^{12}$

$$
\begin{aligned}
U^{*} & =\frac{2}{\theta_{b}+2}\left(1-\frac{n+3}{2} c_{b}-c_{s}\right) \\
V^{*} & =\frac{\theta_{b}}{\theta_{b}+2}\left(1-\frac{n+3}{2} c_{b}-c_{s}\right)-\frac{n+1}{2} c_{s}-\frac{n}{n-1}\left(c_{b}+c_{s}\right)
\end{aligned}
$$

\footnotetext{
${ }^{12}$ In limit equilibrium, we also obtain $W_{1}^{*}=V^{*} / \theta_{s}$ and $W_{2}^{*}=W_{1}^{*}-\frac{n+1}{2} c_{s}$. Together with the free entry conditions and equation (12), one can pin down the market tightness $\theta, \theta_{b}$ and $\theta_{s}$.
} 
It follows that

$$
U^{*}+V^{*}=1-\frac{n}{n-1}\left(c_{b}+c_{s}\right)-\frac{n+3}{2}\left(c_{b}+c_{s}\right)
$$

which is same as in (15). Moreover, one can easily verify that the limit equilibrium commission $\phi^{*}$ is indeed given by (13).

\section{Appendix B: Seller Brokers with Noisy Commu- nication}

In the text, we assume that after the costly first showing, the broker learns perfectly the buyer's type. This appendix analyzes the case where the communication between the broker and the buyer is noisy. We show that our earlier equilibrium characterization for seller brokers with perfect learning remains valid qualitatively under noisy communication.

We model noisy communication as follows. If the buyer likes the first house that he is shown by the broker, he will meet with the seller to buy it, but if he does not like it, the broker is imperfectly informed as to what is his preferred type of house. Assume that the broker learns a set of houses, $\Theta$, of cardinality $k$ that the buyer's preferred house lies in. The set $\Theta$ contains the buyer's preferred house and each broker also randomly draws $k-1$ other types of houses from the $n-2$ house types (excluding the preferred type and the first house). The communication is more precise for a smaller $k$, and we have the special case of perfect learning if $k=1$. We assume that the set $\Theta$ is random and independent across buyer-broker pairs.

As in the previous section, we assume for now that (i) buyers and sellers will not trade directly, (ii) sellers will not pretend to be brokers with two houses, (iii) buyers will not pretend to be brokers with one house, and (iv) brokers will not go to the buyers' market unless they have two different types of houses in their inventory. Later we will specify conditions under which the incentive conditions (i)-(iv) hold.

We use the same notations $\left(V, V_{a}, V_{b}, W_{1}, W_{2}, U\right)$ to denote continuation values of sellers, brokers, and buyers at the end of period $\Delta$. Since noisy communication is relevant only in the buyers' market, the functional equations relating to the sellers' markets, $V, V_{b}$, and $W_{1}$ are the same as in the Section 4.

The functional equations pertaining to the buyers' market, $V_{a}, W_{2}$ and $U$, may be different under noisy communication. Consider a broker with two houses who search for buyers in the buyers' market. Once the broker meets a buyer, they incur inspection and showing costs to see the first house. If the buyer likes the first house, 
he will proceed to meet with the seller to buy the house. If he does not like the first house, the broker learns that the buyer type may be one of the $k$ types in set $\Theta$. If the broker's second house is in set $\Theta$, she will show it to the buyer. If the buyer likes the second house, he will buy it. Otherwise they will separate. They will also separate if the second house is not in $\Theta$. As before, after a seller signs up a seller broker, we assume that all future showing costs are incurred by the broker rather than the seller, except that, when the broker finds a perfect match for the house, the seller incurs one last showing cost to complete the trade.

First, we argue that the seller's functional equation when she has a broker, $V_{a}$, is unchanged as in the case of perfect learning. The reason is that she does not incur any extra showing cost associated with noisy communication. Her only showing cost in the buyers' market occurs when the broker has found a match of her house with a buyer which is the same as in the perfect learning case. So as before, $V_{a}$ is:

$$
V_{a}=\frac{1}{1+r \Delta}\left[m_{b} \Delta\left(\frac{1}{n}\left(p-c_{s}\right)+\frac{1}{n} V_{b}\right)+\left(1-m_{b} \Delta \frac{2}{n}\right) V_{a}\right]
$$

Next consider a buyer who randomly meets a broker with two houses. First, he incurs a cost $c_{b}$ to talk to the broker and inspect the first house. If he likes the house, he meets with the seller and buys it. If he does not like the first house and the second house is in $\Theta$, the buyer incurs another cost $c_{b}$ to see the house. If he likes it, which happens with probability $1 / k$, he will meet the seller and buy the house at a negotiated price $p$. Otherwise, they separate. Thus the functional equation for a buyer in the buyer's market, $U$, is:

$$
U=\frac{1}{1+r \Delta}\left[\begin{array}{c}
\frac{m_{b}}{\theta_{b}} \Delta\left(-c_{b}+\frac{1}{n}\left(1-p-c_{b}\right)+\frac{n-1}{n} \frac{k}{n-1}\left(-c_{b}+\frac{1}{k}\left(1-p-c_{b}\right)\right)\right) \\
+\left(1-\frac{m_{b}}{\theta_{b}} \Delta \frac{2}{n}\right) U
\end{array}\right]
$$

Compared with the perfect learning case, the buyer incurs an additional expected inspection cost of $\frac{k-1}{n} c_{b}$ where $\frac{k-1}{n}$ is the probability that he will see a second house which does not fit.

Finally, consider the problem of the broker with two houses who meets a buyer. He incurs $c_{s}$ to show the first house. The house fits the buyer with probability $\frac{1}{n}$. With probability $\frac{n-1}{n}$, the first house does not fit. In this case, he shows the second house with probability $\frac{k}{n-1}$. The second showing will succeed with probability $\frac{1}{k}$. If the buyer does not buy a house from the broker's clients (which occurs with probability $\frac{n-2}{n}$ ), the broker has to look for another buyer. Thus the functional equation for the broker with two houses is:

$$
W_{2}=\frac{1}{1+r \Delta}\left[m_{b} \Delta\left(-\left(1+\frac{k}{n}\right) c_{s}+\frac{2}{n} W_{1}\right)+\left(1-m_{b} \Delta \frac{2}{n}\right) W_{2}\right]
$$


Compared with the perfect learning case, the broker incurs an additional expected showing cost of $\frac{k-1}{n} c_{s}$ where $\frac{k-1}{n}$ is the probability that he will show a second house which does not fit the buyer.

As in the previous section, when $r \rightarrow 0$, the brokers must be making zero expected profit per completed transaction. Thus the commission a broker receives to sell a house is equal to the expected search costs incurred by the broker. Assuming the broker already has the first house, the limit commission will be:

$$
\phi^{*}=\frac{n}{n-1} c_{b}+\frac{n}{2}\left(1+\frac{n-1}{n} \frac{k}{n-1}\right) c_{s}=\frac{n}{n-1} c_{b}+\frac{n+k}{2} c_{s}
$$

The intuition behind $\phi$ is as follows. The broker still needs to meet $n /(n-1)$ sellers in order to pick up the second house and each time he incurs an inspection cost $c_{b}$, which explains the first term. When the broker goes to the buyers' market, he needs to meet $n / 2$ buyers on average in order to make a sale. When a broker meets a buyer, he incurs a showing $\operatorname{cost} c_{s}$ to show the first house, and if the first house does not fit but the second house lies in the set $\Theta$ (which incurs with probability $\frac{n-1}{n} \frac{k}{n-1}$ ), the broker incurs another showing cost to show the second house, which explains the second term.

In the steady state, the number of brokers picking up houses successfully must be equal to the number of brokers selling houses successfully. We also impose free entry conditions for sellers and brokers.

We derive all our equilibrium continuation values for general $r$, and then take the limit. The limit equilibrium total welfare when the broker's learning is imperfect is given by

$$
U^{*}+V^{*}=1-\frac{n}{n-1}\left(c_{s}+c_{b}\right)-\frac{n+k+2}{2}\left(c_{s}+c_{b}\right)
$$

As in the case with perfect communication, a successful transaction takes $\frac{n}{n-1}$ inspections on average in the sellers' market because a broker picks up a new seller with probability $\frac{n-1}{n}$. As we argue above when we calculate the commission (30), the expected number of searches with brokers for a buyer to find a house he likes is $\frac{n+k}{2}$. For each one of these searches the buyer and broker incurs a cost. Finally there is the final showing of house by the seller to the buyer, during which one more cost of each type is incurred. Thus, we arrive at the above equation.

By comparing the two expressions (31) and (5), we conclude that brokers with noisy communication are welfare improving if

$$
n \geq \frac{n}{n-1}+\frac{n+k+2}{2} \Leftrightarrow n^{2}-(k+5) n+k+2 \geq 0 .
$$

A sufficient condition is $n \geq k+5$. 
As in the case of perfect learning, we need to check incentive compatibility conditions for sellers, buyers and brokers. Notice that when $n \geq k+5$ the joint payoffs of buyers and sellers are higher in dealing with brokers compared to trading directly. Therefore, either the seller or the buyer will be worse off by trading directly. Therefore, we only need to worry about incentive conditions (ii)-(iv).

Since the analysis here is analogous to the one in the previous section, we report the results directly and omit the details. A seller will not pretend to be a broker with two clients and approach buyers directly if

$$
\frac{c_{b}}{c_{s}} \leq \frac{n^{2}-(k+5) n+k+2}{2 n} .
$$

A buyer will not pretend to be a broker with one client and search sellers directly if

$$
\frac{c_{b}}{c_{s}} \geq \frac{(n+k)(n-1)}{n^{2}-(k+5) n+k+2} .
$$

Finally, a broker with one house will not immediately go to the buyers' market to look for a buyer if

$$
\frac{c_{b}}{c_{s}} \leq \frac{(n-k)(n-1)}{2 n} .
$$

To summarize, the broker's incentive condition (34) is implied by the seller's incentive condition (32) for all $n \geq 2$. Therefore, all parties' incentive conditions are satisfied if $n \geq k+5$ and

$$
\frac{(n+k)(n-1)}{n^{2}-(k+5) n+k+2} \leq \frac{c_{b}}{c_{s}} \leq \frac{n^{2}-(k+5) n+k+2}{2 n} .
$$

The set of cost ratio $c_{b} / c_{s}$ that satisfies above constraints is non-empty as long as $n$ is large relative to $k$. When $n$ is large relative to $k$, the second inequality in (35) is always satisfied, while the buyer's IC constraint is also satisfied if $c_{b}$ is relatively higher than $c_{s}$. To summarize our analysis with noisy communication, we have

Proposition 3 Suppose the communication between brokers and buyers is noisy. A search equilibrium with seller brokers exists and improves social welfare if $n \geq k+5$ and condition (35) holds.

It is intuitive that if the broker learns less from costly inspections (i.e., a higher $k$ ) we need a higher heterogeneity (i.e., a higher $n$ ) in order for brokers to exist. As is clear from our analysis, our results with noisy communication are qualitatively similar to the case with perfect learning. 


\section{Appendix C: Search with Buyer Brokers}

This appendix sketches the functional equations and the analysis of incentive conditions in the case of buyer brokers. Let $U$ be the continuation value of a buyer without an broker at the end of period $\Delta, U_{a}$ be the continuation value of a buyer contracted with a broker who has another client, and $U_{b}$ be the continuation value of a buyer who has to return to the buyers' market with his broker without having bought a good so that his broker can pick up another buyer. Then we have

$$
\begin{aligned}
U & =\frac{1}{1+r \Delta}\left[\frac{m_{b}}{\theta_{b}} \Delta\left(-c_{b}+\frac{n-1}{n}\left(U_{a}-\phi\right)\right)+\left(1-\frac{m_{b}}{\theta_{b}} \Delta \frac{n-1}{n}\right) U\right], \\
U_{a} & =\frac{1}{1+r \Delta}\left[\frac{m_{s}}{\theta_{s}} \Delta\left(\frac{1}{n}\left(1-p-c_{b}\right)+\frac{1}{n} U_{b}\right)+\left(1-\frac{m_{s}}{\theta_{s}} \Delta \frac{2}{n}\right) U_{a}\right], \\
U_{b} & =\frac{1}{1+r \Delta}\left[m_{b} \Delta\left(\frac{n-1}{n} U_{a}\right)+\left(1-m_{b} \Delta \frac{n-1}{n}\right) U_{b}\right],
\end{aligned}
$$

where $\phi$ is the commission a buyer has to pay to his broker, and $p$ is the price of the good charged to a buyer. Notice that when the broker finds an appropriate good for one of her two buyers, this buyer still has to inspect the good in order to verify that his preference matches the type of the good. That is why there is a $c_{b}$ in the equation of $U_{a}$.

With abuse of notation, let $W_{1}$ and $W_{2}$ be the continuation value of a broker with one buyer and a broker with two buyers at the end of period $\Delta$, respectively:

$$
\begin{aligned}
& W_{1}=\frac{1}{1+r \Delta}\left[m_{b} \Delta\left(-c_{s}+\frac{n-1}{n}\left(W_{2}+\phi\right)\right)+\left(1-m_{b} \Delta \frac{n-1}{n}\right) W_{1}\right] \\
& W_{2}=\frac{1}{1+r \Delta}\left[\frac{m_{s}}{\theta_{s}} \Delta\left(-c_{b}+\frac{2}{n} W_{1}\right)+\left(1-\frac{m_{s}}{\theta_{s}} \Delta \frac{2}{n}\right) W_{2}\right]
\end{aligned}
$$

Finally, let $V$ be the continuation value of a seller being unmatched at the end of period $\Delta$ :

$$
V=\frac{1}{1+r \Delta}\left[m_{s} \Delta\left(-c_{s}+\frac{2}{n}\left(p-c_{s}\right)\right)+\left(1-m_{s} \Delta \frac{2}{n}\right) V\right] .
$$

Notice that, after the broker finds out the seller's good is a good match with one of broker's clients (with probability $2 / n$ ), the seller still needs to incur one more show $\operatorname{cost} c_{s}$ when showing it to the client.

As in the case of seller brokers, we can follow the standard procedure to obtain the limit solution with buyer brokers:

$$
V^{*}=p^{*}-\frac{n+2}{2} c_{s} \text { and } U^{*}=1-p^{*}-\phi^{*}-\frac{2 n-1}{n-1} c_{b}
$$


where $\phi^{*}$ is the limit commission fee and $p^{*}$ is the limit transaction price. Moreover, in order ensure the existence of the limit continuation value for buyer brokers, we must have

$$
\phi^{*}=\frac{n}{n-1} c_{s}+\frac{n}{2} c_{b},
$$

which will ensure that the broker's expected profit per transaction is zero. Therefore, the total social welfare is

$$
U^{*}+V^{*}=1-\frac{n+2}{2}\left(c_{s}+c_{b}\right)-\frac{n}{n-1}\left(c_{s}+c_{b}\right)
$$

As in the case of seller brokers, we need to check incentive compatibility conditions for sellers, buyers and brokers. Notice that when $n \geq 5$ the joint payoffs of buyers and sellers are higher in dealing with brokers compared to trading directly. Therefore, either the seller or the buyer will be worse off by trading directly. Therefore, we only need to worry about incentive conditions (ii)-(iv).

The seller can pretend to be a broker with one client and approach buyers directly. The seller will not pretend to be a broker if

$$
\phi^{*}=\frac{n}{n-1} c_{s}+\frac{n}{2} c_{b} \leq(n+1) c_{s}-\left(\frac{n}{2}+1\right) c_{s},
$$

which reduces to

$$
\frac{c_{b}}{c_{s}} \leq \frac{n-3}{n-1} .
$$

A buyer can pretend to be a broker with two buyers and buy a good directly from a seller at price $p$. In order to keep the buyers' incentives, we need

$$
\phi^{*}=\frac{n}{n-1} c_{s}+\frac{n}{2} c_{b} \leq n c_{b}-\left(\frac{n}{n-1}+1\right) c_{b},
$$

which reduces to

$$
\frac{c_{b}}{c_{s}} \geq \frac{2 n}{n^{2}-5 n+2}
$$

For brokers, we first need to make sure that the broker will represent two buyers with different preferences. For this we need a condition

$$
c_{s}+\frac{n}{n-1} c_{s}+\frac{n}{2} c_{b} \leq c_{s}+n c_{b}
$$

which is equivalent to

$$
\frac{c_{b}}{c_{s}} \geq \frac{2}{n-1} .
$$

Second, we also need to insure that a broker with one good will not immediately go to the sellers' market to look for a seller. A broker with one buyer will not go to the seller's market directly if

$$
\frac{n}{n-1} c_{s}+\frac{n}{2} c_{b} \leq c_{s}+n c_{b}
$$


which is equivalent to

$$
\frac{c_{b}}{c_{s}} \geq \frac{2}{n(n-1)}
$$

Notice that the broker's incentive conditions (38) and (39) are implied by the seller's incentive condition (37) for all $n \geq 2$. Therefore, all parties' incentive conditions are satisfied if $n \geq 5$ and

$$
\frac{2 n}{n^{2}-5 n+2} \leq \frac{c_{b}}{c_{s}} \leq \frac{n-3}{n-1} .
$$

The last condition is exactly condition (25) in the text.

\section{References}

[1] Albrecht, James W., Anderson, Axel, Smith, Eric and Vroman, Susan B (2007), "Opportunistic Matching in the Housing Market," International Economic Review 48 (2): 641-664.

[2] Atakan, Alp A. (2006), "Assortative Matching with Explicit Search Costs." Econometrica 74(3): 667-681.

[3] Baryla, Edward A, and Zumpano, Leonard V. (1995), "Buyer search duration in the residential real estate market: The role of the real estate agent," Journal of Real Estate Research, 10(1), 1.

[4] Bernheim, B. D, J. Meer (2008), "How Much Value Do Real Estate Brokers Add? A Case Study," National Bureau of Economic Research.

[5] Biglaiser, Gary (1993), "Middlemen as Experts." RAND Journal of Economics 24(2): 212-223.

[6] Bikhchandani, Sushil, David Hirshleifer, and Ivo Welch (1998), "Learning from the Behavior of Others: Conformity, Fads, and Informational Cascades," Journal of Economic Perspectives 12 (3): 151-170.

[7] Blume, Andreas, and Oliver Board (2012), "Language Barriers," Econometrica, forthcoming.

[8] Burdett, Ken, and Melvyn G. Coles (1997), "Marriage and Class," Quarterly Journal of Economics 112 (1): 141-168. 
[9] Camera, Gabriele and Alain Delacroix (2004), "Trade Mechanism Selection in Markets with Frictions," Review of Economic Dynamics 7(4), 851-868.

[10] Diamond, Douglas. 1984. "Financial Intermediation and Delegated Monitoring." Review of Economic Studies 51: 393-414.

[11] Elder, H.W. and Zumpano, L.V. and Baryla, E.A (2000), "Buyer Brokers: Do They Make A Difference? Their Influence on Selling Price and Search duration," Real Estate Economics, 28(2): 337-362.

[12] Findlay, W. and Coverdill, J. E. (2002), Headhunters: Matchmaking in the Labor Market. Ithaca, NY: Cornell University Press.

[13] Hendel, I., A. Nevo, and F. Ortalo-Magne (2009), "The Relative Performance of Real Estate Marketing Platforms: MLS versus fsbomadison.com," American Economic Review 99 (5): 1878-1898.

[14] Li, Yiting (1998), "Middlemen and Private Information," Journal of Monetary Economics, vol. 42, no. 1 (August), pp. 131-159.

[15] Johri, Alok and John Leach (2002), "Middlemen and the Allocation of Heterogeneous Goods," International Economic Review 43: 347-361.

[16] Lipman, Barton (2009), "Why is Language Vague?" Working Paper, Boston University.

[17] Rogerson, Richard, Robert Shimer, and Randall Wright (2005), "Searchtheoretic Models of the Labor Market: A Survey," Journal of Economic Literature 43(4): 959-988.

[18] Rubinstein, Ariel, and Asher Wolinsky (1987), "Middlemen," Quarterly Journal of Economics: 581-594.

[19] Rust, John, and George Hall (2003), "Middlemen versus Market Makers: A Theory of Competitive Exchange." Journal of Political Economy 111(2): 353403.

[20] Shevchenko, Andrei (2004), "Middlemen," International Economic Review 45 (1): $1-24$.

[21] Shimer, Robert, and Lones Smith (2000), "Assortative Matching and Search," Econometrica 68 (2): 343-369. 
[22] Spulber, Daniel F. (1996), "Market Making by Price-setting Firms." Review of Economic Studies: 559-580.

[23] Spulber, Daniel F. (2009), The Theory of the Firm: Microeconomics with Endogenous Entrepreneurs, Firms, Markets, and Organizations. Cambridge University Press.

[24] Wolinsky, Asher (1983), "Retail Trade Concentration due to Consumers' Imperfect Information," The Bell Journal of Economics 14 (1): 275-282.

[25] Wheaton, William C. (1990), "Vacancy, Search, and Prices in a Housing Market Matching Model," Journal of Political Economy 98 (6): 1270-1292.

[26] Yavas, Abdullah (1992), "Marketmakers vs. Matchmakers," Journal of Financial Intermediation 2: 33-58. 